\title{
PENGARUH KECERDASAN INTERPERSONAL DAN KONSISTENSI DIRI TERHADAP PRESTASI BELAJAR MATEMATIKA
}

\author{
Meinar Komala Dewi \\ PAUD Diva Kemuning, Jln. Kemuning Dalam I, RT.007 RW.06, \\ Kelurahan Pejaten Timur, Kecamatan Pasar Minggu, Jakarta Selatan. \\ e-mail: mhea.maniez@gmail.com
}

\begin{abstract}
Abstrak: Pengaruh Kecerdasan Interpersonal dan Konsistensi Diri terhadap Prestasi Belajar Matematika. Tujuan dari penelitian yang dilaksanakan pada bulan Mei 2016 ini adalah untuk mengetahui pengaruh kecerdasan interpersonal dan konsistensi diri terhadap prestasi belajar matematika pada peserta didik kelas $\mathrm{X}$ di SMA Bunda Kandung Jakarta. Metode penelitian yang digunakan adalah metode survai korelasional. Populasi dalam penelitian adalah semua peserta didik kelas X di SMA Bunda Kandung yang terdiri dari 2 kelas dengan jumlah 48 orang peserta didik. Teknik pengambilan sampel pada penelitian ini adalah sampling jenuh, sehingga yang menjadi responden dalam penelitian ini adalah 48 orang peserta didik. Pengumpulan data dilakukan dengan mengambil nilai Ujian Tengah Semester (UTS) Genap untuk variabel prestasi belajar matematika dan pengisian kuesioner oleh peserta didik untuk variabel kecerdasan interpersonal dan variabel konsistensi diri. Analisis data dilakukan dengan analisis statistik deskriptif dan analisis statistik inferensial dengan regresi ganda. Berdasarkan hasil pengujian hipotesis dengan menggunakan uji $\mathrm{F}$, menunjukkan $\mathrm{F}_{\text {hitung }}=11,55$ dan $\mathrm{F}_{\text {tabel }}=3,20$ pada taraf signifikansi $\alpha=0,05$ yang berarti $\mathrm{F}_{\text {hitung }}>\mathrm{F}_{\text {tabel }}$, sehingga peneliti dapat menarik simpulan bahwa terdapat pengaruh yang signifikan kecerdasan interpersonal dan konsistensi diri secara bersama-sama terhadap prestasi belajar matematika pada peserta didik kelas X di SMA Bunda Kandung Jakarta.
\end{abstract}

\section{Kata Kunci: Kecerdasan Interpersonal, Konsistensi Diri, Prestasi Belajar Matematika.}

\begin{abstract}
The impacts of interpersonal intelligence and self consistency on mathematical learning achievement. This research was conducted in Mei 2016. This research is aimed to acknowledging the impacts of interpersonal intelligence and self consistency on mathematical learning achievement. The research was conduted on students X grade in SMA Bunda Kandung. The method used is correlational survey. Population in this research is all students $X$ grade in SMA Bunda Kandung from two class with 48 respondents. The data was taken from even mid test on variables of mathematical learning achievement and questionnaire on variables of interpersonal intelligence and self consistency. Data analyzed used is descriptive statistic analysis and inferensial statistic with double regression. Based on hypothesis analysis on $\mathrm{f}_{\text {test }}$, $f_{\text {count }}>f_{\text {table. }}$ So it can be concluded that there are significant impacts of both interpersonal intelligence and self consistency all together on mathematical learning achievement of the students $\mathrm{X}$ grade in SMA Bunda Kandung.
\end{abstract}

Keywords: Interpersonal Intelligence, Self Consistency, Mathematical Learning Achievement 


\section{PENDAHULUAN}

Pendidikan merupakan suatu berkah dari Sang Maha Pencipta terhadap ciptaannya. Manusia adalah satu-satunya makhluk yang ditakdirkan untuk memeroleh pendidikan. Perolehan pendidikan bukanlah merupakan ikatan terhadap manusia tetapi justru untuk pembebasan manusia dari hakikatnya sebagai makhluk yang bebas dan berakal budi. Sebagai makhluk alamiah yang dilahirkan ke dalam lingkungan alamiahnya, manusia diberikan kebebasan untuk menentukan sendiri posisinya di dalam lingkungan alamiah itu. Di sinilah terletak kebebasan dan keterikatan manusia di dalam proses pengembangan kemanusiaannya.

Berbagai kegiatan yang dilaksanakan tersusun secara terencana dan terorganisir agar tercapai tujuan pendidikan di sekolah. Sebagai lembaga pendidikan formal, sekolah merupakan tempat pengembangan ilmu pengetahuan, kecakapan, keterampilan, nilai dan sikap yang diberikan secara lengkap kepada generasi muda. Hal ini dilakukan untuk membantu perkembangan potensi dan kemampuan agar bermanfaat bagi kepentingan hidupnya. Kegiatan-kegiatan di sekolah bertujuan menghasilkan perubahanperubahan positif pada peserta didik dalam bentuk proses belajar dan pembelajaran.

Pembelajaran di sekolah mencakup beberapa mata pelajaran, dimana salah satunya adalah pelajaran matematika. Matematika merupakan kunci utama dari pengetahuanpengetahuan lain yang dipelajari di sekolah. Tujuan dari pendidikan matematika pada jenjang pendidikan dasar dan menengah adalah menekankan pada penataan nalar dan pembentukan kepribadian peserta didik agar dapat menerapkan atau menggunakan matematika dalam kehidupannya (Soedjadi, 2000: 42). Dengan demikian, matematika menjadi mata pelajaran yang sangat penting dalam pendidikan dan wajib dipelajari pada setiap jenjang pendidikan yang dijalani peserta didik.

Setiap individu mempunyai pandangan yang berbeda tentang pelajaran matematika. Ada yang memandang matematika sebagai mata pelajaran menyenangkan dan ada juga yang memandang matematika sebagai pelajaran sulit. Bagi peserta didik yang menganggap matematika menyenangkan, akan tumbuh motivasi dalam dirinya untuk mempelajari matematika dan optimis dalam menyelesaikan masalah-masalah yang bersifat menantang dalam pelajaran matematika. Sebaliknya, bagi peserta didik yang menganggap matematika sulit, akan bersikap pesimis dalam menyelesaikan masalah matematika dan kurang termotivasi untuk mempelajarinya. Sikap-sikap tersebut akan memengaruhi hasil yang mereka capai dalam proses belajar.

Proses belajar di Sekolah adalah proses yang sifatnya kompleks dan menyeluruh. Banyak orang yang berpendapat bahwa untuk meraih hasil yang tinggi dalam belajar, seseorang harus memiliki Intelligence Quotient (IQ) yang tinggi, kerena IQ merupakan faktor potensial yang akan memudahkan dalam belajar dan pada akhirnya akan menghasilkan prestasi belajar yang optimal. Faktor yang mempengaruhi prestasi belajar peserta didik menurut Ahmadi dan Supriyono (2004: 138) yaitu faktor internal dan faktor eksternal. Faktor internal meliputi kecerdasan, motivasi, kebiasaan, kecemasan, dan minat. Faktor eksternal meliputi lingkungan keluarga, lingkungan sekolah, lingkungan tempat tinggal di masyarakat, dan keadaan sosial ekonomi. 
Kecerdasan interpersonal termasuk dalam faktor internal dari diri peserta didik yang memengaruhi prestasi belajar peserta didik. Kecerdasan interpersonal adalah kecerdasan yang melibatkan keterampilan untuk bekerja sama dengan orang lain dan berkomunikasi dengan baik secara verbal dan nonverbal. Kecerdasan interpersonal juga sering disebut sebagai kecerdasan sosial, selain kemampuan menjalin persahabatan yang akrab dengan teman, juga mencakup kemampuan seperti memimpin, mengorganisir, menangani perselisihan antarteman, memperoleh simpati dari peserta didik yang lain, dan sebagainya. Orang yang memiliki kecerdasan interpersonal yang rendah dapat memunculkan konflik interpersonal. Hal ini ditegaskan oleh Sullivan (Chaplin, 2000: 257) bahwa penyakit mental dan perkembangan kepribadian lebih banyak ditentukan oleh interaksi interpersonalnya daripada oleh faktor-faktor konstitusionalnya.

Konsistensi diri merupakan salah satu faktor yang mempengaruhi prestasi belajar peserta didik dalam pelajaran matematika selain kecerdasan interpersonal. Jika dihubungkan antara matematika dan konsistensi, sepertinya dua kata ini memiliki keterkaitan yang sangat erat. Matematika adalah ilmu yang sistematik dan terstruktur. Sehingga orang yang mempelajarinya diharapkan menjadi seorang yang lebih terstruktur serta terencana. Seseorang yang memiliki konsistensi diri yang baik memiliki pandangan hidup yang jelas dan terarah. Untuk itu biasanya mereka akan selalu membuat rencanarencana untuk setiap apa yang akan mereka lakukan. Bisa dikatakan bahwa seseorang yang memelajari matematika secara tidak langsung dia sedang belajar untuk menjadi seseorang yang konsisten.
Peserta didik yang memiliki tingkat konsistensi yang rendah, biasanya memiliki prestasi yang rendah pula. Konsistensi diri berkaitan erat dengan prinsip yang diambil. Seseorang yang memegang teguh prinsip tergolong orang yang memiliki konsistensi diri. Hal ini berarti bahwa orang tersebut telah memiliki konsistensi diri yang baik. Salah satu konsistensi diri yang baik adalah menerapkan sikap disiplin di dalam hidupnya. Dengan adanya sikap disiplin, maka seseorang dapat mencapai tujuannya secara lebih efektif. Sesuai dengan penelitian yang telah dilakukan oleh Leonard (2015) menyatakan bahwa seseorang yang memiliki sikap konsistensi diri, ditandai dengan adanya disiplin belajar yang baik, sehingga prestasi belajar matematikanya akan meningkat. Dengan kata lain dampak dari sikap konsistensi diri adalah meningkatnya prestasi belajar matematika.

\section{METODE}

Penelitian kuantitatif ini dilaksanakan di SMA Bunda Kandung yang beralamat di Jalan Poltangan Raya No.41 RT.002 RW.10, Kelurahan Pejaten Timur, Kecamatan Pasar Minggu, Jakarta Selatan. Penelitian yang dilaksanakan pada bulan Maret s.d. Juli di tahun 2016 ini merupakan penelitian survai korelasional dengan analisis regresi ganda. Adapun desain penelitian digambarkan sebagai berikut:

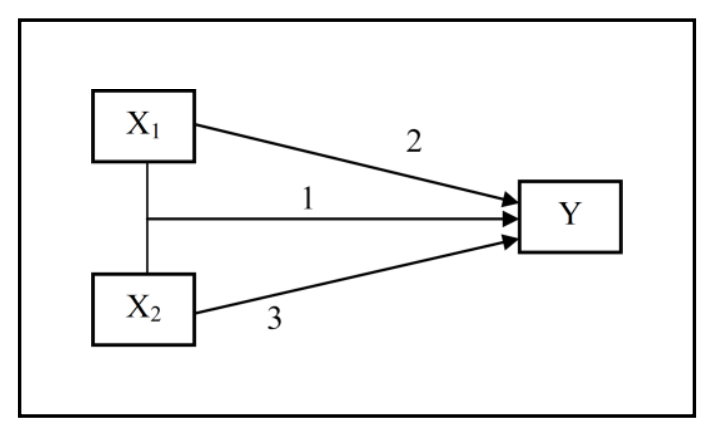

Gambar 1. Desain Penelitian 
Keterangan:

$\mathrm{X}_{1}$ : Kecerdasan Interpersonal

$\mathrm{X}_{2}$ : Konsistensi Diri

$\mathrm{Y}$ : Prestasi Belajar Matematika

1 : Pengaruh Kecerdasan Interpersonal dan Konsistensi Diri Secara Bersama-sama terhadap Prestasi Belajar Matematika

2 : Pengaruh Kecerdasan Interpersonal terhadap Prestasi Belajar Matematika

3 : Pengaruh Konsistensi Diri terhadap Prestasi Belajar Matematika

Populasi target dalam penelitian ini adalah seluruh peserta didik SMA Bunda Kandung Jakarta. Populasi terjangkau dalam penelitian ini adalah peserta didik kelas $\mathrm{X}$ di SMA Bunda Kandung pada tahun pelajaran 2015/2016 dengan jumlah peserta didik 48 orang. Sampel pada penelitian ini adalah 48 peserta didik kelas $\mathrm{X}$ yang terdiri dari 2 kelas akan diambil seluruhnya sebagai sampel. Teknik pengambilan sampel pada penelitian ini adalah sampling jenuh. Menurut Sugiyono (2001: 61), "Sampling jenuh adalah teknik penentuan sampel bila semua anggota populasi digunakan sebagai sampel". Variabel yang digunakan pada penelitian ini terdiri atas tiga variabel yang terdiri dari dua variabel bebas dan satu variabel terikat. Adapun variabel-variabel penelitiannya adalah: (1) variabel bebas yang pertama, yaitu kecerdasan interpersonal peserta didik; (2) variabel bebas yang kedua, yaitu konsistensi diri peserta didik pada pelajaran matematika; dan (3) variabel terikat, yaitu prestasi belajar matematika.

Kemudian teknik pengumpulan data yang digunakan dalam penelitian ini adalah: (1) prestasi belajar matematika diambil dari nilai UTS semester genap; (2) kecerdasan interpersonal peserta didik diambil menggunakan angket atau kuesioner; dan (3) konsistensi diri peserta didik diambil menggunakan angket atau kuesioner. Perangkat instrumen pada penelitian ini adalah bentuk nontes. Instrumen nontes digunakan untuk variabel kecerdasan interpersonal dan konsistensi diri. Instrumen penelitian divalidasi secara empiris, dimana instrumen diujicobakan ke 30 orang peserta didik yang tidak masuk dalam sampel penelitian.

Teknik analisis terhadap data hasil penelitian yang dalam hal ini berupa nilai prestasi belajar matematika serta perolehan total skor atas angket kecerdasan interpersonal dan konsistensi diri peserta didik dilakukan secara deskriptif dan inferensial. Secara deskriptif, data hasil penelitian dianalisis untuk skor mean, median, dan modus. Adapun maksud analisis skor mean, median, dan modus adalah untuk mendeskripsikan perolehan ukuran pemusatan data dari peserta didik yang menjadi subjek penelitian. Secara inferensial, data hasil penelitian dianalisis menggunakan uji $\boldsymbol{F}$ dan uji $\boldsymbol{t}$, dengan terlebih dahulu diuji untuk persyaratan analisisnya yaitu uji normalitas, uji linearitas, dan uji multikolinearitas. Perhitungan data hasil penelitian secara keseluruhan dilakukan dengan menggunakan bantuan software Ms. Excel.

\section{HASIL DAN PEMBAHASAN}

\section{Hasil Penelitian}

Karakteristik responden merupakan peserta didik kelas $\mathrm{X}$ di SMA Bunda Kandung yang berjumlah 48 peserta didik. Dari 48 orang responden, peserta didik laki-laki berjumlah 21 orang dan peserta didik 
perempuan berjumlah 27 orang. Adapun umur responden dalam penelitian berada pada kisaran 16 s.d. 17 tahun. Data hasil penelitian ini dianalisis secara deskriptif dan inferensial. Secara deskriptif, data hasil penelitian ini ditampilkan dalam tabel 1 .

Tabel 1. Ringkasan Hasil Perhitungan Statistik Deskriptif

\begin{tabular}{lccc}
\hline \multicolumn{1}{c}{ Kelompok } & Mean & Median & Modus \\
\hline Prestasi Belajar Matematika & 78,25 & 80,75 & 77,00 \\
Kecerdasan Interpersonal & 97,33 & 98,07 & 99,28 \\
Konsistensi Diri & 84,77 & 83,66 & 81,79 \\
\hline
\end{tabular}

Sumber: Data primer yang diolah

Selanjutnya data hasil penelitian dianalisis secara inferensial untuk pengujian hipotesis, namun terlebih dahulu harus dilakukan uji persyaratan analisis data, yang meliputi uji normalitas, uji linearitas, dan uji multikolinearitas. Pengujian normalitas dilakukan untuk mengetahui apakah data yang diperoleh untuk setiap kelompok sampel berasal dari populasi yang berdistribusi normal atau tidak. Perhitungan uji normalitas dilakukan dengan uji Chi Square yang perhitungan secara teknisnya menggunakan bantuan software Ms. Excel. Adapun kriteria pengujian normalitas adalah jika $\chi_{\text {hitung }}^{2}<\chi_{\text {tabel }}^{2}$, maka distribusi data dinyatakan normal dan sebaliknya jika $\chi_{\text {hitung }}^{2}>\chi_{\text {tabel }}^{2}$, maka distribusi data dinyatakan tidak normal. Berdasarkan tabel 2 di bawah ini, terlihat bahwa seluruh data kelompok sampel yang diteliti berasal dari populasi yang berdistribusi normal.

Tabel 2. Ringkasan Hasil Perhitungan Uji Normalitas Data

\begin{tabular}{lcccc}
\hline \multicolumn{1}{c}{ Kelompok Data } & $\begin{array}{c}\text { Jumlah } \\
\text { Sampel }\end{array}$ & $\chi^{2}$ hitung & $\chi^{2}$ tabel & Simpulan \\
\hline Prestasi Belajar Matematika & 48 & 10,48 & 12,59 & Berdistribusi Normal \\
Kecerdasan Interpersonal & 48 & 4,51 & 12,59 & Berdistribusi Normal \\
Konsistensi Diri & 48 & 5,83 & 12,59 & Berdistribusi Normal \\
\hline
\end{tabular}

Sumber: Data primer yang diolah

Setelah uji normalitas data, selanjutnya dilakukan uji persyaratan analisis untuk uji linearitas. Pengujian linearitas dimaksudkan mengetahui apakah dua variabel berpola linear antara satu sama lainnya. Dengan kata lain, uji linearitas dilakukan dalam rangka menguji model persamaan suatu variabel terikat atas suatu variabel bebas. Uji linearitas dilakukan dengan cara membandingkan nilai $\mathrm{F}_{\text {hitung }}$ dan $\mathrm{F}_{\text {tabel}}$, dengan kriteria: Terima $\mathrm{H}_{0}$, jika
$\mathrm{F}_{\text {hitung }}<\mathrm{F}_{\text {tabel }} \rightarrow$ regresi berpola linier atau Tolak $\mathrm{H}_{0}$, jika $\mathrm{F}_{\text {hitung }}>$ $\mathrm{F}_{\text {tabel }} \rightarrow$ regresi berpola tidak linier. Oleh karena pada penelitian ini terdapat satu variabel terikat (Y) dan dua variabel bebas $\left(\mathrm{X}_{1}\right.$ dan $\left.\mathrm{X}_{2}\right)$, maka ada dua uji linearitas. Pertama uji linearitas $\mathrm{X}_{1}$ terhadap $\mathrm{Y}$, yang mana berdasarkan tabel 3, terlihat bahwa $F_{\text {hitung }}<\mathrm{F}_{\text {tabel }}$, sehingga dapat disimpulkan bahwa terdapat hubungan yang linear antara kecerdasan interpersonal $\left(\mathrm{X}_{1}\right)$ dengan 
prestasi belajar matematika (Y). Yang kedua uji linearitas $\mathrm{X}_{2}$ terhadap $\mathrm{Y}$, yang mana berdasarkan tabel 4, terlihat bahwa $\mathrm{F}_{\text {hitung }}<\mathrm{F}_{\text {tabel }}$, sehingga dapat disimpulkan bahwa terdapat hubungan yang linear antara konsistensi diri $\left(\mathrm{X}_{2}\right)$ dengan prestasi belajar matematika (Y).

Tabel 3. Ringkasan Hasil Uji Linearitas Kecerdasan Interpersonal terhadap Prestasi Belajar Matematika

\begin{tabular}{llllll}
\hline \multicolumn{1}{c}{ Sumber Varian $(\mathrm{SV})$} & $\mathrm{Dk}$ & \multicolumn{1}{c}{$\mathrm{JK}$} & \multicolumn{1}{c}{ RJK } & $\mathrm{F}_{\text {hitung }}$ & $\mathrm{F}_{\text {tabel }}$ \\
\hline Total & $\mathrm{N}$ & 296379 & & & \\
Regresi (a) & 1 & 293437,69 & 293437,69 & & \\
Regresi (b | a) & 1 & 275,49 & 275,49 & -0.83 & 2,00 \\
Residu & 46 & 2665,89 & 57,95 & & \\
Tuna Cocok & 25 & $-288408,21$ & $-11536,33$ & & \\
Kesalahan/Error & 21 & 291074,03 & 13860,67 & & \\
\hline
\end{tabular}

Sumber: Data primer yang diolah

Tabel 4. Ringkasan Hasil Uji Linearitas Konsistensi Diri terhadap Prestasi Belajar Matematika

\begin{tabular}{lcllll}
\hline \multicolumn{1}{c}{ Sumber Varian (SV) } & \multicolumn{1}{c}{$\mathrm{Dk}$} & \multicolumn{1}{c}{$\mathrm{JK}$} & \multicolumn{1}{c}{$\mathrm{RJK}$} & $\mathrm{F}_{\text {hitung }}$ & $\mathrm{F}_{\text {tabel }}$ \\
\hline Total & $\mathrm{N}$ & 296379 & & & \\
Regresi (a) & 1 & 295474,08 & 295474,08 & & \\
Regresi (b | a) & 1 & $-11,08$ & $-11,08$ & -0.84 & 2,00 \\
Residu & 46 & 2952,39 & 64,18 & & \\
Tuna Cocok & 25 & $-541092,04$ & $-21643,68$ & & \\
Kesalahan/Error & 21 & 544044,43 & 25906,88 & & \\
\hline
\end{tabular}

Sumber: Data primer yang diolah

Setelah uji linearitas terpenuhi, selanjutnya dilakukan uji persyaratan yang terakhir yaitu uji multikolinearitas. Uji multikolinearitas dimaksudkan untuk mengetahui hubungan antar variabel bebas yaitu ada atau tidaknya hubungan yang kuat antara variabel kecerdasan interpersonal dengan konsistensi diri. Kriteria pengujiannya adalah kedua variabel bebas tidak terdapat masalah multikolinearitas jika nilai Variance Inflation Factor (VIF) < 10. Berdasarkan tabel 5, terlihat bahwa nilai Variance Inflation Factor (VIF) < 10 , berarti variabel terbebas dari asumsi klasik multikolinearitas atau dengan kata lain kedua variabel bebas tidak terdapat masalah multikolinearitas.

Tabel 5. Ringkasan Hasil Uji Multikolinearitas

\begin{tabular}{llcc}
\hline & \multicolumn{2}{c}{ Collinearity } & Statistics \\
Model & Tolerance & VIF \\
\hline 1 & Kecerdasan Interpersonal & 0,495 & 1,324 \\
& Konsistensi Diri & 0,495 & 1,324 \\
\hline Sumber: Data primer yang diolah & &
\end{tabular}

Setelah semua uji persyaratan analisis terpenuhi, dilanjutkan dengan pengujian hipotesis, yaitu uji pengaruh kecerdasan interpersonal dan konsistensi diri secara bersama-sama terhadap prestasi belajar matematika, uji pengaruh kecerdasan interpersonal terhadap prestasi belajar matematika, dan uji pengaruh konsistensi diri terhadap prestasi belajar matematika. 
Tabel 6. Ringkasan Hasil Uji Korelasi $X_{1}$ dan $X_{2}$ terhadap $Y$

Model Summary

\begin{tabular}{ccccc}
\hline Model & $R$ & $R$ Square & $\begin{array}{c}\text { Adjusted } R \\
\text { Square }\end{array}$ & $\begin{array}{c}\text { Std. Error of } \\
\text { the Estimate }\end{array}$ \\
\hline 1 & 0,357 & 0,128 & 0,089 & 7.552 \\
\hline
\end{tabular}

Sumber: Data primer yang diolah

Tabel 7. Ringkasan Hasil Uji F untuk Pengujian Pengaruh Simultan $X_{1}$ dan $X_{2}$ terhadap $Y$

$A N O V A^{\mathrm{b}}$

\begin{tabular}{llccccc}
\hline \multicolumn{2}{l}{ Model } & \multicolumn{2}{c}{ Sum of } & & & \\
Squares & $d f$ & Mean Square & $F$ & Sig. \\
\hline 1 & Regression & 375.180 & 2 & 187.590 & 3.290 & 0,045 \\
& Residual & 2566.132 & 45 & 57.025 & & \\
& Total & 2941.313 & 47 & & & \\
\hline
\end{tabular}

Sumber: Data primer yang diolah

Tabel 8. Ringkasan Hasil Uji $t$ untuk Pengujian Pengaruh $X_{1}$ terhadap $Y$ dan Pengaruh $X_{2}$ terhadap $Y$

Coefficients $^{\mathrm{a}}$

\begin{tabular}{lccccccccccc}
\hline & \multicolumn{1}{c}{$\begin{array}{c}\text { Unstandardized } \\
\text { Coefficients }\end{array}$} & $\begin{array}{c}\text { Standardized } \\
\text { Coefficients }\end{array}$ & & & \multicolumn{3}{c}{ Correlations } \\
Model & $B$ & Std. Error & Beta & $t$ & Sig. & $\begin{array}{c}\text { Zero- } \\
\text { order }\end{array}$ & Partial & Part \\
\hline $1 \quad$ (Constant) & 48,959 & 11,451 & & 4,276 & 0,000 & & & \\
Kecerdasan Interpersonal & 0,147 & 0,117 & 0,201 & 1,256 & 0,216 & 0,306 & 0,184 & 0,175 \\
$\quad$ Konsistensi Diri & 0,176 & 0,133 & 0,212 & 1,322 & 0,193 & 0,311 & 0,193 & 0,184 \\
\hline
\end{tabular}

Sumber: Data primer yang diolah

Korelasi ganda yang menghubungkan persamaan kecerdasan interpersonal, konsistensi diri, dan prestasi belajar matematika diperoleh dari tabel 6. Berdasarkan tabel 6, diperoleh hasil korelasi ganda kecerdasan interpersonal dan konsistensi diri secara bersama-sama terhadap prestasi belajar matematika adalah 0.357; yang berarti korelasi antara ketiga variabel tersebut tergolong rendah. Koefisien determinasinya sebesar 0,128 atau ada kontribusi sebesar $12,8 \%$ berupa pengaruh kecerdasan interpersonal dan konsistensi diri secara bersama-sama terhadap prestasi belajar matematika.
Selanjutnya adalah pengujian hipotesis regresi ganda $\mathrm{X}_{1}$ dan $\mathrm{X}_{2}$ terhadap $\mathrm{Y}$ dengan uji F. Adapun kriteria pengujiannya adalah $\mathrm{H}_{0}$ diterima jika $F_{\text {hitung }}<F_{\text {tabel }}$ atau $\mathrm{H}_{0}$ ditolak jika $F_{\text {hitung }}>F_{\text {tabel. }}$. Setelah dilakukan perhitungan, diperoleh nilai $\mathrm{F}$ seperti pada tabel 7. Berdasarkan tabel 7, diperoleh nilai $F_{\text {hitung }}=3,290$. Adapun dengan $\mathrm{dk}_{1}=2$ dan $\mathrm{dk}_{2}=45$ diperoleh nilai $F_{\text {tabel }}=3,200$. Oleh karena $\mathrm{F}_{\text {hitung }}>\mathrm{F}_{\text {tabel }}$ maka $\mathrm{H}_{0}$ ditolak. Hal ini berarti bahwa $\mathrm{H}_{0}$ (hipotesis nol) yang menyatakan tidak terdapat pengaruh yang signifikan kecerdasan interpersonal dan konsistensi diri secara 
bersama-sama terhadap prestasi belajar matematika adalah ditolak. Dengan demikian, hipotesis pada penelitian ini yang berbunyi: "terdapat pengaruh yang signifikan kecerdasan interpersonal dan konsistensi diri secara bersama-sama terhadap prestasi belajar matematika" adalah diterima. Dengan kata lain, dapat disimpulkan bahwa terdapat pengaruh yang signifikan kecerdasan interpersonal dan konsistensi diri secara bersama-sama terhadap prestasi belajar matematika.

Adapun persamaan regresi ganda yang diperoleh berdasarkan hasil penelitian ini dapat disusun berdasarkan tabel 8. Berdasarkan tabel 8, dapat disusun persamaan regresi ganda $\widehat{\mathbf{Y}}=48,959+0,147 \mathbf{X}_{\mathbf{1}}+0,176 \mathbf{X}_{\mathbf{2}}$.

Adapun persamaan regresi ganda tersebut dapat diinterpretasikan sebagai berikut: Konstanta sebesar 48,959 menyatakan bahwa jika tidak ada kecerdasan interpersonal dan konsistensi diri, maka prestasi belajar matematika peserta didik diperoleh sebesar 48,959. Atau dengan kata lain prestasi belajar matematika peserta didik diperoleh sebesar 48,959 jika kecerdasan interpersonal dan konsistensi diri diabaikan.

Koefisien regresi kecerdasan interpersonal sebesar 0,147 menyatakan bahwa setiap penambahan 1 satuan, kecerdasan interpersonal peserta didik akan meningkatkan prestasi belajar matematika sebesar 0,147 dengan anggapan konsistensi diri tetap. Berlaku juga sebaliknya, jika kecerdasan interpersonal peserta didik turun 1 satuan, maka prestasi belajar matematika diprediksi turun 0,147 dengan anggapan konsistensi diri tetap.

Koefisien regresi konsistensi diri sebesar 0,176 menyatakan bahwa setiap penambahan 1 satuan, konsistensi diri akan meningkatkan prestasi belajar matematika sebesar 0,176 dengan anggapan kecerdasan interpersonal tetap. Berlaku juga sebaliknya jika konsistensi diri turun 1 satuan, maka prestasi belajar matematika diprediksi mengalami penurunan sebesar 0,240 dengan anggapan kecerdasan interpersonal tetap.

Kemudian nilai $t$ seperti tampak pada tabel 8 , yang mana diperoleh nilai $t_{\text {hitung }}$ untuk kecerdasan interpersonal sebesar 1,256. Pada taraf signifikansi 0,05 dengan $d k=\mathrm{n}-\mathrm{k}-1=48-$ $2-1=45$ diperoleh $t_{\text {tabel }}=2,000$. Dengan demikian $\mathrm{H}_{0}$ diterima karena $\left|t_{\text {hitung }}\right|<t_{\text {tabel }}$, hal ini berarti terdapat pengaruh yang tidak signifikan kecerdasan interpersonal terhadap prestasi belajar matematika. Berikutnya masih tertera pada tabel 8 , nilai $t_{\text {hitung }}$ untuk konsistensi diri sebesar 1,322. Pada taraf signifikansi 0,05 dengan $d k=\mathrm{n}-\mathrm{k}-1=130-2-1=45$ diperoleh $\quad t_{\text {tabel }}=2,000$. Dengan demikian $\mathrm{H}_{0}$ diterima karena $\left|t_{\text {hitung }}\right|<t_{\text {tabel }}$, hal ini berarti terdapat pengaruh yang tidak signifikan konsistensi diri terhadap prestasi belajar matematika.

\section{Pembahasan Hasil Penelitian}

1. Pengaruh kecerdasan interpersonal dan konsistensi diri secara bersamasama terhadap prestasi belajar matematika

Mengacu pada perhitungan data hasil penelitian prestasi belajar matematika, kecerdasan interpersonal, dan konsistensi diri, dapat disimpulkan bahwa ketiga variabel tersebut memiliki pengaruh yang signifikan. Berdasarkan hasil penelitian diketahui bahwa pengaruh signifikan kecerdasan interpesonal dan konsistensi diri secara bersamasama terhadap prestasi belajar matematika, dengan besarnya kontribusi adalah $12,8 \%$. 
Hasil penelitian ini sejalan dengan pendapat Cahyono (2014) bahwa dengan memiliki kecerdasan interpersonal yang baik, peserta didik dapat bekerjasama dalam mengerjakan tugas kelompok, karena kecerdasan interpersonal berpengaruh signifikan terhadap prestasi belajar matematika. Hasil penelitian ini juga sejalan dengan Leonard (2013), yang menyatakan bahwa seseorang yang memiliki konsistensi diri ditandai dengan adanya disiplin belajar yang baik, sehingga prestasi belajar matematika dari seseorang tersebut akan menjadi baik. Berdasarkan hasil penelitian ini, dapat disimpulkan bahwa jika dibangun kecerdasan interpersonal yang baik dan diiringi dengan konsistensi diri yang baik pula, maka secara bersama-sama dapat menjadikan prestasi belajar matematika lebih baik.

2. Pengaruh kecerdasan interpersonal terhadap prestasi belajar matematika

Mengacu pada perhitungan data hasil penelitian untuk prestasi belajar matematika dan kecerdasan interpersonal, dapat disimpulkan bahwa kedua variabel tersebut memiliki pengaruh yang tidak signifikan. Berdasarkan hasil penelitian diketahui bahwa prestasi belajar matematika dipengaruhi oleh kecerdasan interpersonal sebesar $6,2 \%$. Kontribusi ini berdasarkan uji signifikansi, ternyata berpengaruh tidak signifikan.

Hasil penelitian ini tidak sejalan dengan pendapat Cahyono (2014) bahwa dengan memiliki kecerdasan interpersonal yang baik, peserta didik dapat bekerjasama dalam mengerjakan tugas kelompok karena kecerdasan interpersonal berpengaruh signifikan terhadap prestasi belajar matematika. Oleh karena itu, kecerdasan interpersonal yang dimiliki peserta didik harus terus dibangun dengan lebih baik lagi sehingga dapat meningkatkan prestasi belajar matematika secara signifikan. Kecerdasan interpersonal yang harus dibangun adalah mengacu pada instrumen kecerdasan interpersonal berdasarkan penelitian ini. Kecerdasan interpersonal yang dimaksud, diantaranya peka terhadap orang lain, mendengarkan masalah orang lain, dan dapat bekerjasama dengan orang lain. Selain itu, peserta didik juga harus mempunyai sikap sosial yang baik dan mampu meredam emosi serta mampu menilai cara pandang seseorang terhadap diri sendiri secara positif.

3. Pengaruh konsistensi diri terhadap prestasi belajar matematika

Mengacu pada perhitungan data hasil penelitian untuk prestasi belajar matematika dan konsistensi diri, dapat disimpulkan bahwa kedua variabel tersebut memiliki pengaruh yang tidak signifikan. Berdasarkan hasil penelitian diketahui bahwa prestasi belajar matematika dipengaruhi oleh konsistensi diri sebesar 6,5\%. Besarnya kontribusi $6,6 \%$ ini berdasarkan uji signifikansi, ternyata berpengaruh tidak signifikan.

Hasil penelitian ini tidak sejalan dengan Leonard (2013) bahwa seseorang yang memiliki sikap konsistensi diri ditandai dengan adanyan disiplin belajar yang baik, sehingga prestasi belajar matematikanya akan meningkat. Oleh karena itu konsistensi diri yang dimiliki peserta didik harus terus dibangun dengan lebikh baik lagi sehingga dapat meningkatkan prestasi belajar matematika. Konsistensi diri menjadikan peserta didik disiplin dalam belajar sehingga 
dapat meningkatkan prestasi belajar matematika. Konsistensi diri yang harus dibangun adalah mengacu pada instrumen konsistensi diri berdasarkan penelitian ini. Konsistensi diri yang dimaksud diantaranya kesiapan dalam belajar, tanggung jawab sebagai pelajar, dan aktivitas dalam belajar. Selain itu, peserta didik harus menjaga tingkah laku dan kebiasan yang baik.

\section{SIMPULAN DAN SARAN}

\section{Simpulan}

Berdasarkan hasil pengujian hipotesis dan pembahasan hasil penelitian yang sudah dikemukakan, terkait dengan penelitian "Pengaruh Kecerdasan Interpersonal dan Konsistensi Diri terhadap Prestasi Belajar Matematika" dapat disimpulkan sebagai berikut: Terdapat pengaruh yang signifikan kecerdasan interpersonal dan konsistensi diri secara bersama-sama terhadap prestasi belajar matematika peserta didik kelas $X$ di SMA Bunda Kandung Jakarta. Terdapat pengaruh yang tidak signifikan kecerdasan interpersonal terhadap prestasi belajar matematika peserta didik kelas X di SMA Bunda Kandung Jakarta. Terdapat pengaruh yang tidak signifikan konsistensi diri terhadap prestasi belajar matematika peserta didik kelas X di SMA Bunda Kandung Jakarta.

\section{Saran}

Penelitian ini dimaksudkan untuk mengetahui pengaruh kecerdasan interpersonal dan konsistensi diri terhadap prestasi belajar matematika peserta didik kelas X SMA Bunda Kandung Jakarta. Dengan berpedoman pada hasil penelitian yang ada, beberapa saran dapat dituangkan untuk memperbaiki prestasi belajar matematika peserta didik, diantaranya: Kepala sekolah sebagai pimpinan unit organisasi lembaga pendidikan formal harus memiliki kepedulian dan perhatian yang lebih untuk membangun kecerdasan interpersonal dan konsistensi diri peserta didik. Kepala sekolah juga diharapkan mampu membangun lingkungan belajar yang kondusif sehingga diperoleh peningkatan kualitas pendidikan baik secara proses maupun hasil khususnya prestasi belajar matematika. Guru sebagai subjek yang sangat dekat komunikasinya dengan peserta didik harus menjadi teladan. Guru harus memiliki kecerdasan interpersonal yang baik sehingga dapat menjadi teladan dan dapat ditiru peserta didik.

\section{DAFTAR RUJUKAN}

Ahmadi, A. \& Supriyono W. 2004. Psikologi Belajar. Jakarta: Rineka Cipta.

Cahyono. 2014.

Leonard. 2013. Kajian Peran Konsistensi Diri terhadap Prestasi Belajar Matematika. Jurnal Formatif, 3(2): 97-104.

Soedjadi. 2000. Kiat Pendidikan Matematika di Indonesia. Jakarta: Direktorat Jendral Pendidikan Tinggi Departemen Pendidikan Nasional.

Sugiono. 2010. Metode Penelitian Pendidikan Pendekatan Kuantitatif, Kualitatif, dan $R \& D$. Bandung: Alfabeta. 